\title{
Adipose-Derived Mesenchymal Stromal Cells Treated with Interleukin 1 Beta Produced Chondro-Protective Vesicles Able to Fast Penetrate in Cartilage
}

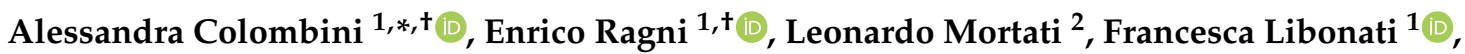 \\ Carlotta Perucca Orfei ${ }^{1}\left(\mathbb{\infty}\right.$, Marco Viganò $^{1}\left(\mathbb{D}\right.$, Marco Brayda-Bruno $^{3}$ and Laura de Girolamo ${ }^{1}(\mathbb{C}$ \\ 1 Laboratorio di Biotecnologie Applicate all'Ortopedia, IRCCS Istituto Ortopedico Galeazzi, \\ I-20161 Milano, Italy; enrico.ragni@grupposandonato.it (E.R.); francesca.libonati@grupposandonato.it (F.L.); \\ carlotta.perucca@grupposandonato.it (C.P.O.); marco.vigano@grupposandonato.it (M.V.); \\ laura.degirolamo@grupposandonato.it (L.d.G.) \\ 2 INRIM-Istituto Nazionale di Ricerca Metrologica, 10135 Torino, Italy; 1.mortati@inrim.it \\ 3 III Spine Surgery-Scoliosis Department, IRCCS Istituto Ortopedico Galeazzi, 20161 Milano, Italy; \\ marco.brayda@spinecaregroup.it \\ * Correspondence: alessandra.colombini@grupposandonato.it; Tel.: +39-02-66214067 \\ + Equally contributed.
}

\section{check for}

updates

Citation: Colombini, A.; Ragni, E.; Mortati, L.; Libonati, F.; Perucca Orfei, C.; Viganò, M.; Brayda-Bruno, M.; de Girolamo, L. Adipose-Derived Mesenchymal Stromal Cells Treated with Interleukin 1 Beta Produced Chondro-Protective Vesicles Able to Fast Penetrate in Cartilage. Cells 2021, 10, 1180. https://doi.org/10.3390/ cells10051180

Academic Editor: Mujib Ullah

Received: 27 April 2021

Accepted: 9 May 2021

Published: 12 May 2021

Publisher's Note: MDPI stays neutral with regard to jurisdictional claims in published maps and institutional affiliations.

Copyright: (c) 2021 by the authors. Licensee MDPI, Basel, Switzerland. This article is an open access article distributed under the terms and conditions of the Creative Commons Attribution (CC BY) license (https:/ / creativecommons.org/licenses/by/ $4.0 /)$.
Abstract: The study of the miRNA cargo embedded in extracellular vesicles (EVs) released from adipose-derived mesenchymal stromal cells (ASC) preconditioned with IL-1 $\beta$, an inflammatory stimulus driving osteoarthritis (OA), along with EVs-cartilage dynamic interaction represent poorly explored fields and are the purpose of the present research. ASCs were isolated from subcutaneous adipose tissue and EVs collected by ultracentrifugation. Shuttled miRNAs were scored by highthroughput screening and analyzed through bioinformatics approach that predicted the potentially modulated OA-related pathways. Fluorescently labeled EVs incorporation into OA cartilage explants was followed in vitro by time-lapse coherent anti-Stokes Raman scattering; second harmonic generation and two-photon excited fluorescence. After IL-1 $\beta$ preconditioning, 7 miRNA were up-regulated, 4 down-regulated, 37 activated and 17 silenced. Bioinformatics allowed to identify miRNAs and target genes mainly involved in Wnt, Notch, TGF $\beta$ and Indian hedgehog (IHH) pathways, cartilage homeostasis, immune/inflammatory responses, cell senescence and autophagy. As well, ASC-EVs steadily diffuse in cartilage cells and matrix, reaching a plateau $16 \mathrm{~h}$ after administration. Overall, ASCs preconditioned with IL-1 $\beta$ allows secretion of EVs embedded with a chondro-protective miRNA cargo, able to fast penetrate in collagen-rich areas of cartilage with tissue saturation in a day. Further functional studies exploring the EVs dose-effects are needed to achieve clinical relevance.

Keywords: adipose-derived mesenchymal stromal cells; extracellular vesicles; miRNA; interleukin 1 beta; cartilage; osteoarthritis; nonlinear optical microscopy; time-lapse

\section{Introduction}

Osteoarthritis (OA) is a chronic pathology of the whole joint [1], leading to a progressive loss of bony, cartilaginous and synovial tissues homeostasis, driven and sustained by catabolic and inflammatory process.

Adipose-derived mesenchymal stromal cells (ASCs) based therapy has been used in some clinical trials to treat OA patients [2] as a tool potentially acting on several pathological targets given their immunomodulatory and trophic ability. In fact, ASCs respond in an adaptive way to inflammatory stimuli, in particular to interleukin-1 $\beta$ (IL-1 $\beta$ ) [3], a central molecular regulator of the complex network of proteolytic enzymes, chemokines and cytokines leading the degenerative processes of OA [4]. In vitro, ASCs showed high responsiveness to IL-1 $\beta$ stimulation, resulting in the up-regulation of matrix metalloproteases 
(MMPs)-1, -3 and -13 , angiogenic and mitogenic factors, cytokines controlling production, differentiation and function of macrophages, as well as molecules belonging to the insulin-like growth factor (IGF), platelet-derived growth factor (PDGF) and transforming growth factor (TGF) families and pro- (IL-1 $\beta$ and IL-8) and anti- (IL-1Ra) inflammatory cytokines [3].

In basal conditions, ASC released extracellular vesicles (EVs) with a preponderance of microRNAs (miRNAs) involved in OA cartilage and synovium protection (40\%) over less than $10 \%$ of those involved in degenerative processes [5]. In addition, the EV cargo can be further modulated by preconditioning the mesenchymal stem cells (MSCs) with stimuli resembling the in vivo pathological environment [6-8]. ASCs inflammatory priming with interferon $\gamma(\mathrm{IFN} \gamma)$ determined a production of a $34.7 \%$ chondro-protective versus a $13.3 \%$ chondro-destructive miRNAs and a secretion of $26.2 \%$ versus $4.5 \%$ of M2- versus M1-macrophages-related miRNAs [9].

In addition to these evidences, a large number of miRNAs are able to modulate IL-1 $\beta$ induced extracellular cartilage matrix degradation and are involved in the control of the initiation and progression of OA [10-12]. For these reasons, the ASC preconditioning with IL-1 $\beta$ could represent an already unexplored strategy to produce functional EVs exploitable as cell-free therapeutic tool to induce whole joint homeostasis and prevent further OA progression.

In this specific context, it is essential to analyze also the EV interaction with the tissue and the cells resident therein to better understand their real therapeutic potential. Recently, the ability of ASC-EVs to penetrate in chondrocyte micromasses and cartilage explants from osteoarthritic patients was shown through a novel, real-time, microscopy technique [13].

The aim of the present study was to characterize the EVs obtained from ASCs treated with IL-1 $\beta$ in term of shuttled miRNAs and their kinetic of penetration in OA cartilage to understand the potential of this cell-free approach for treatment of OA.

\section{Materials and Methods}

\subsection{ASCs Isolation, Expansion and Cartilage Collection}

The study was approved by the local Institutional Review Board (M-SPER-015) and tissue samples were collected after obtaining patients' informed written consent.

Subcutaneous adipose tissue from local hip fat deposit of three patients who underwent total hip replacement ( 2 females 53 and $56 \mathrm{y} / \mathrm{o}$ and 1 male $41 \mathrm{y} / \mathrm{o}$ ) was collected and ASCs isolated by enzymatic digestion $\left(37^{\circ} \mathrm{C}, 30 \mathrm{~min}\right.$ with $0.075 \% w / v$ type I collagenase (Worthington Biochemical, Lakewood, NJ, USA) [14].

The cells were cultured in minimum essential medium ( $\alpha$ MEM), supplemented with $10 \%$ fetal bovine serum (FBS) (Lonza, Basel, Switzerland), $0.29 \mathrm{mg} / \mathrm{mL}$ L-glutamine, $100 \mathrm{U} / \mathrm{mL}$ penicillin, $100 \mathrm{\mu g} / \mathrm{mL}$ streptomycin, $10 \mathrm{mM}$ 4-(2-hydroxyethyl)piperazine1-ethanesulfonic acid (HEPES), $1 \mathrm{mM}$ sodium pyruvate (all reagents from Thermo Fisher Scientific, Waltham, Massachusetts, USA) and $5 \mathrm{ng} / \mathrm{mL}$ fibroblast growth factor 2 (PeproTech, Rocky Hill, NJ, USA) at $37^{\circ} \mathrm{C}, 5 \% \mathrm{CO}_{2}$, and $95 \%$ humidity, expanded until passage 3 . and characterized as previously reported $[3,15]$.

Articular cartilage slices (100-250 $\mu \mathrm{m} \times 3-5 \mathrm{~mm}$ length) from non-weight bearing areas of the femoral heads/necks of other two females and one male affected by OA (Kellgren Lawrence III-IV, 38-54 y/o) undergoing total hip arthroplasty were collected and used for kinetic tests performed through a real-time, microscopy technique within two day.

\subsection{EVs Isolation}

The ASCs at $90 \%$ confluency were primed with $1 \mathrm{ng} / \mathrm{mL}$ of IL- $1 \beta$ for $48 \mathrm{~h}$ following a standardized protocol [3]. After this treatment, the cells were washed three times with PBS before adding serum free medium for $48 \mathrm{~h}$. The culture supernatants $(30 \mathrm{~mL})$ were collected and differentially centrifuged at $376 \times g-15^{\prime}$ for debris and floating cells removal, $1000 \times g-15^{\prime}, 2000 \times g-15^{\prime}$ and twice at $4000 \times g-15^{\prime}$ each at $4{ }^{\circ} \mathrm{C}$ to obtain cleared products. The cleared supernatants were ultracentrifuged at $100,000 \times g-3 \mathrm{~h}, 4^{\circ} \mathrm{C}$ in 
a 70Ti rotor (Beckman Coulter, Brea, California, CA, USA) to obtain EVs. EV pellets were suspended in $100 \mu \mathrm{L}$ phosphate-buffered saline (PBS), counted and characterized as previously reported [15].

\subsection{EV-Embedded miRNA Expression}

The EV pellets were dissolved by Trizol and ribonucleic acid (RNA) was obtained by using miRNeasy Kit and RNeasy CleanUp Kit (Qiagen, Hilden, Germany). Synthetic ath-miR-159a as a spike-in were added during the extraction to each sample to monitor the technical variability during the processes.

Reverse transcription and preamplification were performed to prepare complementary desoxyribonucleic acids (cDNAs) used for real-time polymerase chain reaction (PCR) with the QuantStudio ${ }^{\mathrm{TM}} 12$ K Flex OpenArray ${ }^{\circledR}$ Platform (QS12Kflex, Thermo Fisher Scientific). The Open Array covered 754 human miRNA sequences from the Sanger miRBase v21 Gene, divided into A and B panels.

\section{4. miRNA Data Normalization}

The miRNA expression was analyzed by Expression Suite Software (Life Technologies). The spike-in was used to equalize A and B panels of the Open Array and for the equalization of technical differences during the whole process [16]. CRT of 27 was considered as a threshold for the presence/absence of amplification. Global mean, calculated from miRNAs amplified in all samples, was the normalization method [17]. The relative quantification $2-\triangle \mathrm{CRT}$ was used to determine the miRNA expression, shown as mean values $\pm \mathrm{SD}$.

\section{5. miRNA Differential Expression Analysis}

Paired t-test was applied to normalized CRT (Table S1) to identify miRNAs up- or down-regulated in IL-1 $\beta$ treated respect to untreated ASCs. At the same time, miRNAs with CRT above the set threshold only in IL-1 $\beta$ treated or only in untreated ASCs were considered as activated or silenced, respectively.

\section{6. miRNA Target Prediction Analysis}

The bioinformatics Mientournet tool (http:/ / userver.bio.uniroma1.it/apps/mienturnet/, accessed on 1 February 2021) [18] was used for validated target prediction analysis, considering miRTarBase database for experimentally validated miRNA-target interactions and miRNAs upor down-regulated and activated or silenced by IL-1 $\beta$ treatment separately.

As first step, miRNA-target enrichment was performed by setting as threshold at least two gene-miRNA interactions and the lists of miRNAs with common targets and of genes targeted by the same miRNAs were retrieved (Supplementary Tables S2-S5). Functional enrichment analysis was conducted by exploiting three different bioinformatics opensource tools: KEGG pathway, Reactome and Wikipathway, allowing for visualization and interpretation of pathways to support basic research. Significant pathways overrepresented within the targets of selected miRNAs are listed and represented by circles, starting with those that are common to at least two miRNAs. Circles are colored according to the significance of the enrichment and their size is proportional to the number of involved targets.

Ingenuity Pathway Analysis (IPA; Ingenuity ${ }^{\circledR}$ Systems, Qiagen, Germany, www. ingenuity.com, accessed on 1 February 2021) was used to identify the experimentally observed miRNA involved in OA, by using the miRNA Target Filter tool.

\subsection{Time-Lapse Microscopy for EVs Incorporation in Cartilage}

The EV-cartilage explants co-cultures were performed by using $25 \times 10^{8}$ carboxyfluorescein succinimidyl ester (CFSE)-labeled EVs per $\mu \mathrm{L}$. The samples were followed over a period of $40 \mathrm{~h}$. The imaged cartilage portion had $279.7 \mu \mathrm{m}$ (405 pixels) width, $350.8 \mu \mathrm{m}$ (508 pixels) height, a total depth of $210.5 \mu \mathrm{m}$ (20 Z slices, 3 images per slice) and was measured each $15 \mathrm{~min}(0.25 \mathrm{~h})$ for a total of 65 timeframes $(16 \mathrm{~h})$. 
The multimodal microscope allowed to collect images with Coherent Anti-Stokes Raman Scattering (CARS) for the cellular lipidic structures combined with Second Harmonic Generation (SHG) techniques for the collagen of the extracellular matrix [19] and Two-Photon Excitation Fluorescence (TPEF) for the EVs [13].

In the microscopy setup CARS signal was targeted at the $\mathrm{CH} 2$ stretching mode $\left(2848 \mathrm{~cm}^{-1}\right)$, using a Nd:YVO4 laser emitting 10 ps pulses centered at $1064 \mathrm{~nm}$ (Picotrain, HighQLaser, Austria) as the Stokes field and the signal output of an Optical Parametric Oscillator (Levante Emerald OPO) (APE, Berlin, Germany) tuned at about $817 \mathrm{~nm}$ with a pulse width of 6 ps as the pump field. The laser repetition rate was $76 \mathrm{MHz}$. The two beams entered into an upright microscope (BX51WI, Olympus, Tokyo, Japan) through the scanning unit (FluoView FV300, Olympus, Tokyo, Japan). The same OPO signal output at $817 \mathrm{~nm}$ was used as excitation source of the TPEF and SHG processes. The total average power at the sample of the excitation pulses was set to about $40 \mathrm{~mW}$. The excitation beams were focused on living samples using a water immersion objective (LUMPLFLN 40XW NA $=0.8$, W.D. $=3.3 \mathrm{~mm}$, Olympus) that was cleaned and sterilized with a solution $70 \%$ ethanol in water $(\mathrm{v} / \mathrm{v})$ before the experiment. A condenser objective (UPLSAPO $10 \times$ objective $\mathrm{NA}=0.4$, Olympus) was used to collect forward CARS signal at about $663 \mathrm{~nm}$ and SHG signal at about $408 \mathrm{~nm}$ that were optically filtered and then detected using two separate PMTs (R3896, Hamamatsu, Japan). The TPEF signal was acquired in a back-scattering geometry (epi-detection).

A microscope stage incubator (Okolab, Napoli, Italy) maintained $37{ }^{\circ} \mathrm{C}, 5 \% \mathrm{CO}_{2}$ and the humidity range between 50 and 95\% through an Active Humidity Controller.

\subsection{Multimodal Microscopy Data Analysis}

The depth of EV penetration during the time-lapse together with the average occupied area and volume were computed using a custom-made ImageJ plugins processing the 3D images as already described [13].

\section{Results}

The ASCs were characterized in two previously published works by our group, showing the expression of characteristic MSC cell-surface antigens, the lack of expression of emato-endothelial markers, their colony forming unit ability and multi-differentiation potential $[3,15]$.

\subsection{IL-1 $\beta$ Preconditioning Modulated the Expression of a Small Amount of miRNAs}

Among all the 754 analyzed miRNAs, 417 miRNA were detected in either basal or primed condition (Table S1). Seven (miR-125a-3p, miR-134-5p, miR-222-5p, miR-146a-5p, miR-155-5p, miR-196b-5p and miR-520c-3p) were significantly up-regulated, in particular miR-146a-5p and miR-520c-3p that showed a Fc over 30, and 4 (miR-191-3p, miR-500a-5p, miR-656-3p and miR1265) were significantly down-regulated by the IL-1 $\beta$ treatment (Table 1 ). Moreover, 37 miRNA were activated and 17 were silenced by the IL-1 $\beta$ stimulus (Table 2 ).

Table 1. Up- or down-regulated miRNAs by the IL-1 $\beta$ treatment. $F_{c}=$ fold change.

\begin{tabular}{cccccc}
\hline & Up-Regulated & & \multicolumn{3}{c}{ Down-Regulated } \\
\hline miRNA & Fc & $p$-Value & miRNA & Fc & $p$-Value \\
\hline miR-125a-3p & 2.2 & 0.04 & miR-191-3p & 0.4 & 0.02 \\
\hline miR-134-5p & 5.7 & 0.007 & miR-500a-5p & 0.5 & 0.05 \\
\hline miR-222-5p & 3.0 & 0.02 & miR-656-3p & 0.3 & 0.01 \\
\hline miR-146a-5p & 33.2 & 0.004 & miR-1265 & & 0.04 \\
\hline miR-155-5p & 4.6 & 0.02 & & & \\
\hline miR-196b-5p & 2.4 & 0.003 & & & \\
\hline miR-520c-3p & 32.2 & 0.05 & & & \\
\hline
\end{tabular}


Table 2. Activated or silenced miRNAs by the IL-1 $\beta$ treatment.

\begin{tabular}{|c|c|}
\hline Activated & Silenced \\
\hline let-7f-2-3p & hsa-let-7f-1-3p \\
\hline let-7i-3p & miR-132-5p \\
\hline miR-100-3p & miR-122-3p \\
\hline miR-10a-3p & miR-130b-5p \\
\hline $\operatorname{miR}-127-5 p$ & $\operatorname{miR}-135 b-5 p$ \\
\hline miR-1282 & miR-142-3p \\
\hline miR-1290 & miR-187-3p \\
\hline miR-1304-5p & miR-194-5p \\
\hline miR-1324 & miR-223-5p \\
\hline miR-133a & miR-23b-3p \\
\hline miR-15b-3p & miR-302d-3p \\
\hline $\operatorname{miR}-181 c-3 p$ & miR-378a-3p \\
\hline miR-200b-3p & miR-518d-3p \\
\hline $\operatorname{miR}-29 b-2-5 p$ & miR-566 \\
\hline miR-326 & miR-589-3p \\
\hline $\operatorname{miR}-361-3 p$ & $\operatorname{miR}-623$ \\
\hline $\mathrm{miR}-376 \mathrm{~b}$ & miR-628-3p \\
\hline \multicolumn{2}{|l|}{$\operatorname{miR}-377-3 p$} \\
\hline \multicolumn{2}{|l|}{ miR-380-3p } \\
\hline \multicolumn{2}{|l|}{$\operatorname{miR}-431-5 p$} \\
\hline \multicolumn{2}{|l|}{$\operatorname{miR}-449 b-5 p$} \\
\hline \multicolumn{2}{|l|}{ miR-483-3p } \\
\hline \multicolumn{2}{|l|}{$\operatorname{miR}-485-5 p$} \\
\hline \multicolumn{2}{|l|}{ miR-489 } \\
\hline \multicolumn{2}{|l|}{ miR-511 } \\
\hline \multicolumn{2}{|l|}{ miR-517a-3p; miR-517b-3p } \\
\hline \multicolumn{2}{|l|}{ miR-519a-3p } \\
\hline \multicolumn{2}{|l|}{ miR-520b } \\
\hline \multicolumn{2}{|l|}{ miR-523-3p } \\
\hline \multicolumn{2}{|l|}{ miR-541-3p } \\
\hline \multicolumn{2}{|l|}{ miR-550a-5p } \\
\hline \multicolumn{2}{|l|}{ miR-551b-5p } \\
\hline \multicolumn{2}{|l|}{ miR-604 } \\
\hline \multicolumn{2}{|l|}{ miR-639 } \\
\hline \multicolumn{2}{|l|}{ miR-646 } \\
\hline \multicolumn{2}{|l|}{$\operatorname{miR}-7-2-3 p$} \\
\hline miR-92a-1-5p & \\
\hline
\end{tabular}




\subsection{IL-1 $\beta$ Up-Regulated/Activated miRNAs Showed Interaction with Pathways and Process Relevant to $O A$}

Among the IL-1 $\beta$ up-regulated miRNA, miR-155-5p followed by miR-146a-5p, miR196b-5p, miR-125a-3p, miR-134-5p and miR-520c-3p showed the highest number of interactions (Table S2).

Bioinformatics analysis evidenced some relevant pathways modulated by IL-1 $\beta$ upregulated miRNA and potentially involved in OA such as Wingless and Int-1 (Wnt), transforming growth factor beta (TGF $\beta$ ), vascular endothelial growth factor (VEGF), interleukin10 (IL-10), type I interferon (IFN1), Hippo and the other pathways related to proliferation, cell stress and lymphocyte mediated immunity (Figure 1).
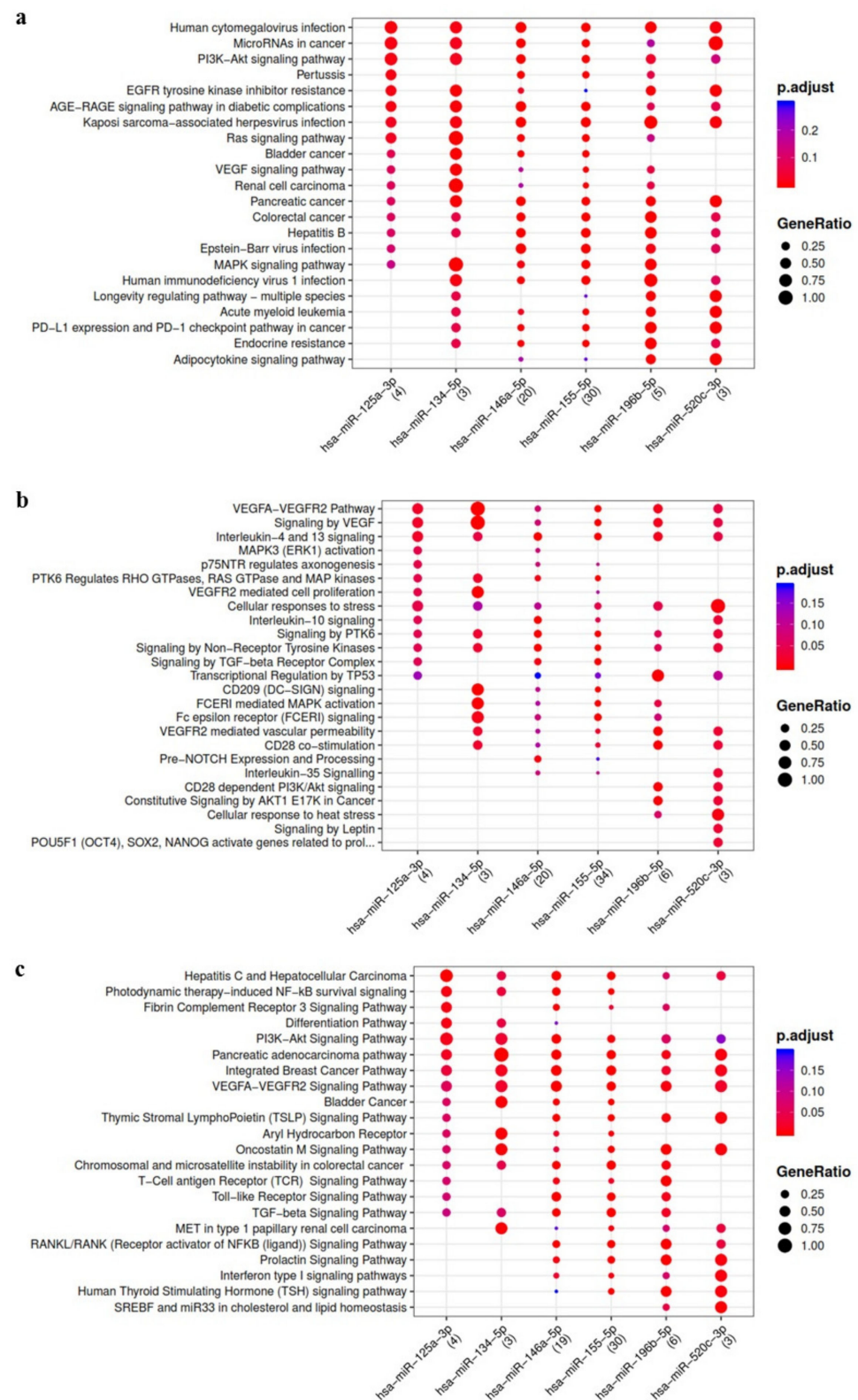

Figure 1. Functional enrichment analysis on miRNA up-regulated in ASC-EVs primed with IL-1 $\beta$. The analysis was conducted by KEGG pathway (a) Reactome (b) and Wikipathway (c). Significant pathways are listed and represented by circles colored according to the significance of the enrichment and their size is proportional to the number of target genes regulating the described signaling pathways. 
Among the miRNAs activated by the treatment with IL-1 $\beta$, miR-133a-3p, miR-483-3p, miR-200b-3p, miR-377-3p, miR-15b-3p, miR-485-5p and miR-519a-3p showed the highest number of interactions (Table S3). These IL-1 $\beta$ activated miRNA putatively modulate hypoxia-inducible factor 1 (HIF1), TGF $\beta$, insulin like growth factor 1 (IGF-1), bone morphogenetic protein (BMP), Notch1, cell cycle, senescence, oxidative stress and endochondral ossification pathways (Figure 2).

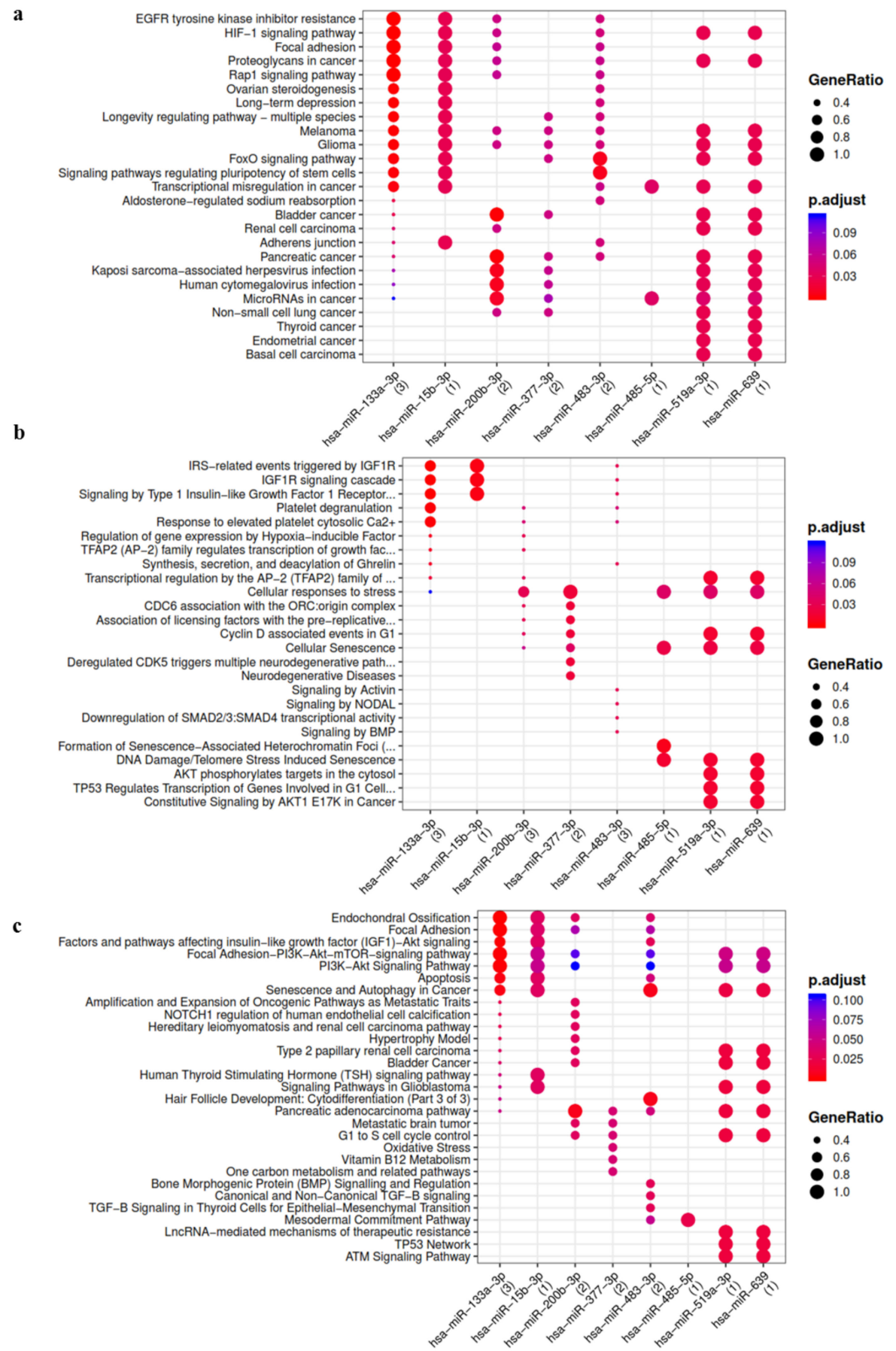

Figure 2. Functional enrichment analysis on miRNA activated in ASC-EVs primed with IL-1 $\beta$. The analysis was conducted by KEGG pathway (a) Reactome (b) and Wikipathway (c). Significant pathways are listed and represented by circles colored according to the significance of the enrichment and their size is proportional to the number of target genes regulating the described signaling pathways. 
On the contrary, IL-1 $\beta$ down-regulated miRNA (Table S4) showed no functional enrichment results.

Finally, concerning miRNA expressed in ASCs and silenced by inflammatory stimulus, miR-23b-3p followed by miR-142-3p, miR-135b-5p, miR-194-5p, miR-302d-3p, miR-378a-3p and miR-223-5p showed the higher number of interactions (Table S5). Notch, TGF $\beta$ and senescence are the pathways modulated by these miRNAs (Figure 3).

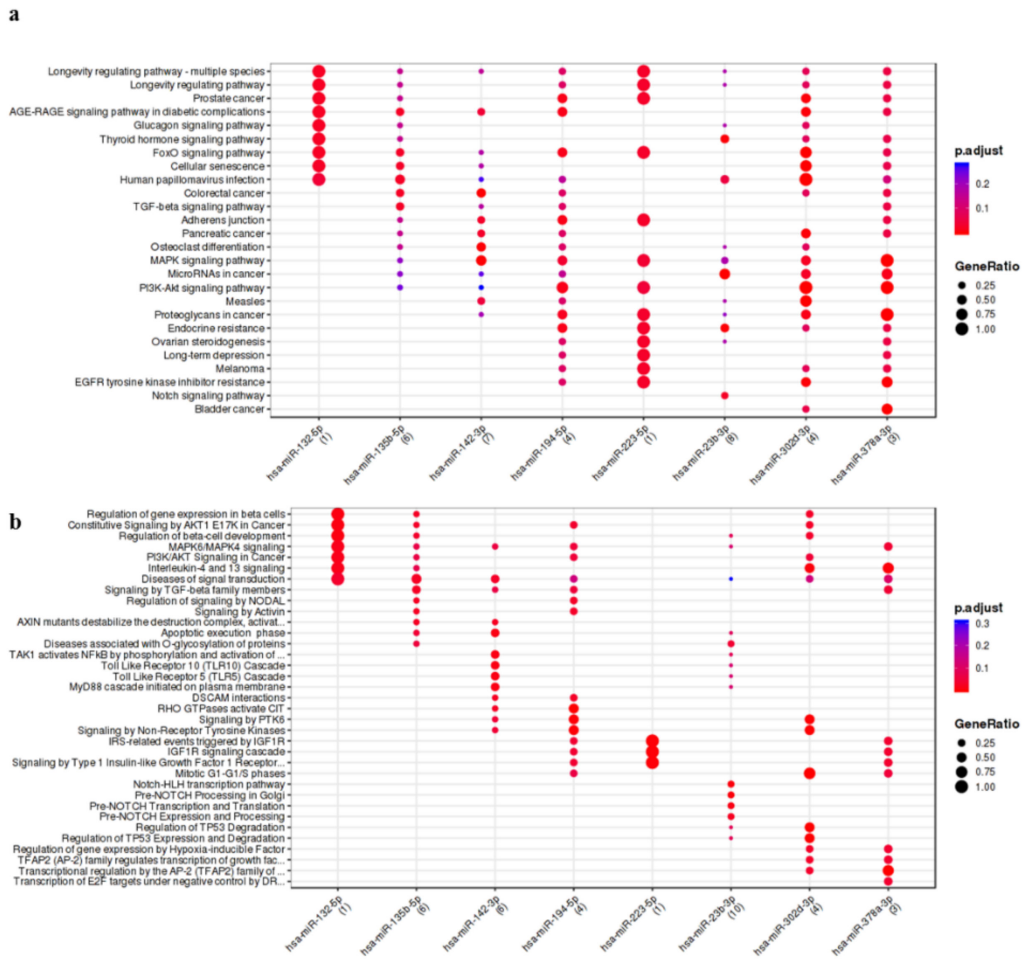

Figure 3. Functional enrichment analysis on miRNA silenced in ASC-EVs primed with IL-1 $\beta$. The analysis was conducted by KEGG pathway (a) and Wikipathway (b). Significant pathways are listed and represented by circles colored according to the significance of the enrichment and their size is proportional to the number of target genes regulating the described signaling pathways.

3.3. OA Focused Analysis Revealed Few miRNAs with a Key Role in the Wnt Pathway and Inflammatory Response

A further analysis focused on miRNA experimentally observed as involved in OA and modulated by IL- $1 \beta$ treatment allowed to identify 2 up-regulated, 4 activated and 4 silenced miRNAs (Table 3) and target genes mainly involved in Wnt pathway, in the regulation of immune and inflammatory responses, in Notch, TGF $\beta$ and Indian hedgehog (IHH) signaling, in cartilage homeostasis and in cell senescence and autophagy. 
Table 3. miRNA experimentally observed as involved in osteoarthritis and modulated by IL-1 $\beta$ treatment.

\begin{tabular}{|c|c|c|c|}
\hline & miRNA & Target Genes & miRNA Properties \\
\hline \multirow{3}{*}{ Up-regulated } & miR-146a-5p & $S M A D 4, V E G F, B c l 2$ & $\begin{array}{l}\text { TGF } \beta \text { signaling inhibition, } \\
\text { modulate chondrocytes } \\
\text { apoptosis/autophagy and } \\
\text { inflammatory functions }\end{array}$ \\
\hline & miR-155-5p & $\begin{array}{l}\text { CEBPB, CTNNB1, } \\
\text { SMAD1, TCF7L2 }\end{array}$ & $\begin{array}{l}\text { Chondroprotective (suppress } \\
\text { MMP-1 and MMP-3 production), } \\
\text { Wnt signaling inhibition, } \\
\text { modulate inflammatory functions }\end{array}$ \\
\hline & miR-520c-3p & DKK1, RELA, SEMA3C & $\begin{array}{l}\text { Wnt signaling activation, } \\
\text { modulate inflammatory functions } \\
\text { and chondrogenesis }\end{array}$ \\
\hline \multirow{7}{*}{ Activated } & miR-127-5p & MMP13 & $\begin{array}{l}\text { Chondroprotective (suppress } \\
\text { MMP-13 production) }\end{array}$ \\
\hline & $\operatorname{miR}-326$ & $S M O$ & Chondroprotective \\
\hline & miR-377-3p & CART1 & Cartilage homeostasis \\
\hline & miR-449b-5p & JAG1, NOTCH1, SIRT1 & $\begin{array}{l}\text { Chondroprotective (NOTHC } \\
\text { signaling inhibition), senescence } \\
\text { dysregulation }\end{array}$ \\
\hline & miR-483-3p & $A C A N$ & Cartilage homeostasis \\
\hline & miR-519a-3p & PRKAA1 & $\begin{array}{l}\text { Senescence and autophagy } \\
\text { dysregulation }\end{array}$ \\
\hline & miR-520b & DKK, RELA & $\begin{array}{l}\text { Wnt signaling activation, } \\
\text { modulate inflammatory functions }\end{array}$ \\
\hline \multirow{4}{*}{ Silenced } & miR-135b-5p & RUNX2, SMAD5 & $\begin{array}{l}\text { Wnt signaling inhibition, } \\
\text { inhibition of osteogenic } \\
\text { differentiation }\end{array}$ \\
\hline & $\operatorname{miR}-23 b-3 p$ & $\begin{array}{l}\text { HES1, NOTCH1, } \\
\text { PRKACB, CRTAP }\end{array}$ & $\begin{array}{l}\text { Chondroprotective (NOTHC } \\
\text { signaling inhibition), cartilage } \\
\text { homeostasis }\end{array}$ \\
\hline & miR-302d-3p & DKK1, RELA & $\begin{array}{l}\text { Wnt signaling activation, } \\
\text { modulate inflammatory functions }\end{array}$ \\
\hline & miR-378a-3p & CASP9 & Marker of late stage OA \\
\hline
\end{tabular}

\subsection{ASC-EVs Diffuse in Both Cells and Surrounding Matrix with Differential Kinetics}

The 3D reconstructions of the sample showed that ASC-EVs penetrated the cartilage explant along the observation time (Figure 4a).

The TPEF signal from the EVs was visible in the tissue already from the early steps of the experiment and further increased for both intensity and spatial distribution during the time-lapse up to $16 \mathrm{~h}$ when the signal reached a plateau.

Average penetration depth, area and volume for each time step showed a transient dynamic that can be better fitted using a function that is a sum of two exponential transients (Equation (1) in Table S6), with respect a single exponential transient (Equation (2) in Table S6) as it can be seen also in Figure $4 \mathrm{~b}$ and from the sum of the squared errors (SSE) parameter that it is lower when Equation (1) is used. Therefore, two distinct kinetics, one faster than the other, differing by one order of magnitude were observed.

EVs penetration showed a shape depending on the morphology of the cartilage, reaching locally about $40 \mu \mathrm{m}$ of depth at the end of experiment (Figure 5a), although there was a comprehensive rise on the penetration of the EVs along the whole sample. 


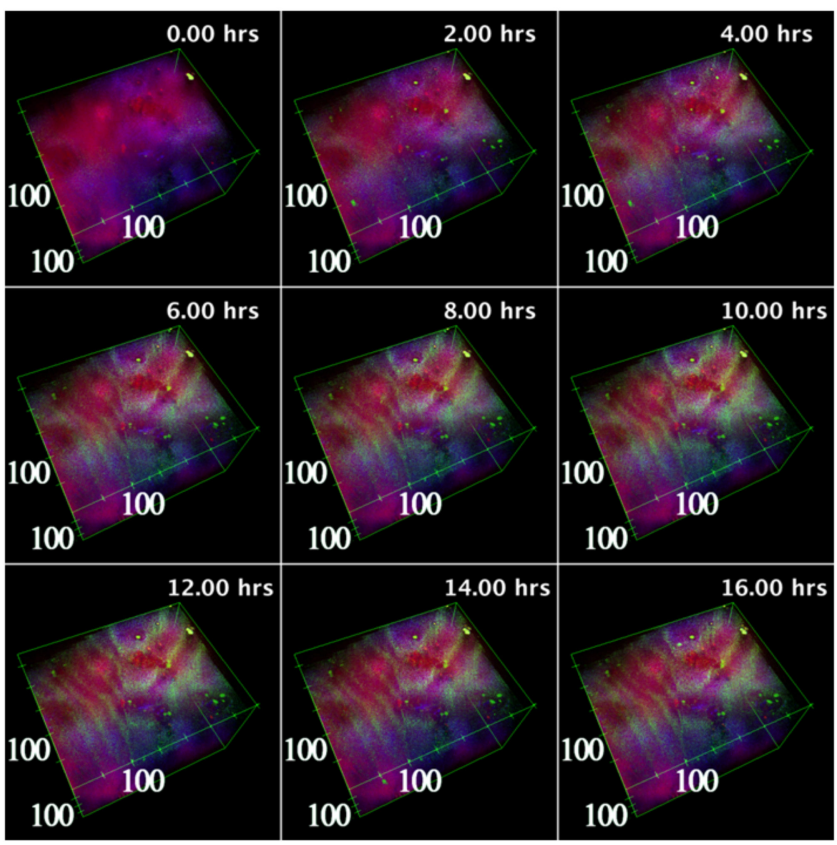

b
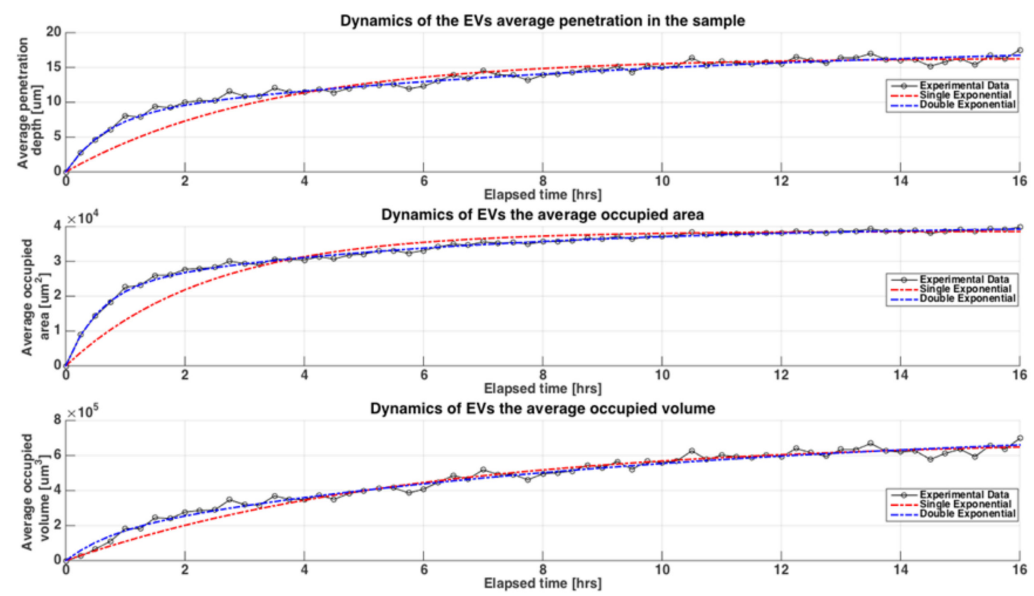

Figure 4. ASC-EVs kinetic of penetration in OA cartilage. (a) 3D reconstructions of the cartilage explant during the time-lapse experiment where the cells and the rich lipidic structures are shown in red (CARS signal at $2848 \mathrm{~cm}^{-1}$ from lipid structures), the collagen rich ECM is shown in blue (SHG signal from collagen) end the EVs are shown in green (TPEF signal from EVs fluorescence stain). In the box is shown the scale in $\mu \mathrm{m}$, while in the upper right corner is depicted the corresponding time of the image during the experiment. The reconstructions are obtained from the acquired images and processed using 3Dviewer with ImageJ. (b) Three graphs of the dynamics of the EVs in the tissue during the time-lapse related to the depth, the area and the volume are showed. For each curve are also plotted the related fitting in blue the double exponential one (Equation (1) in Table S6) and in red the single exponential one (Equation (2) in Table S6). 


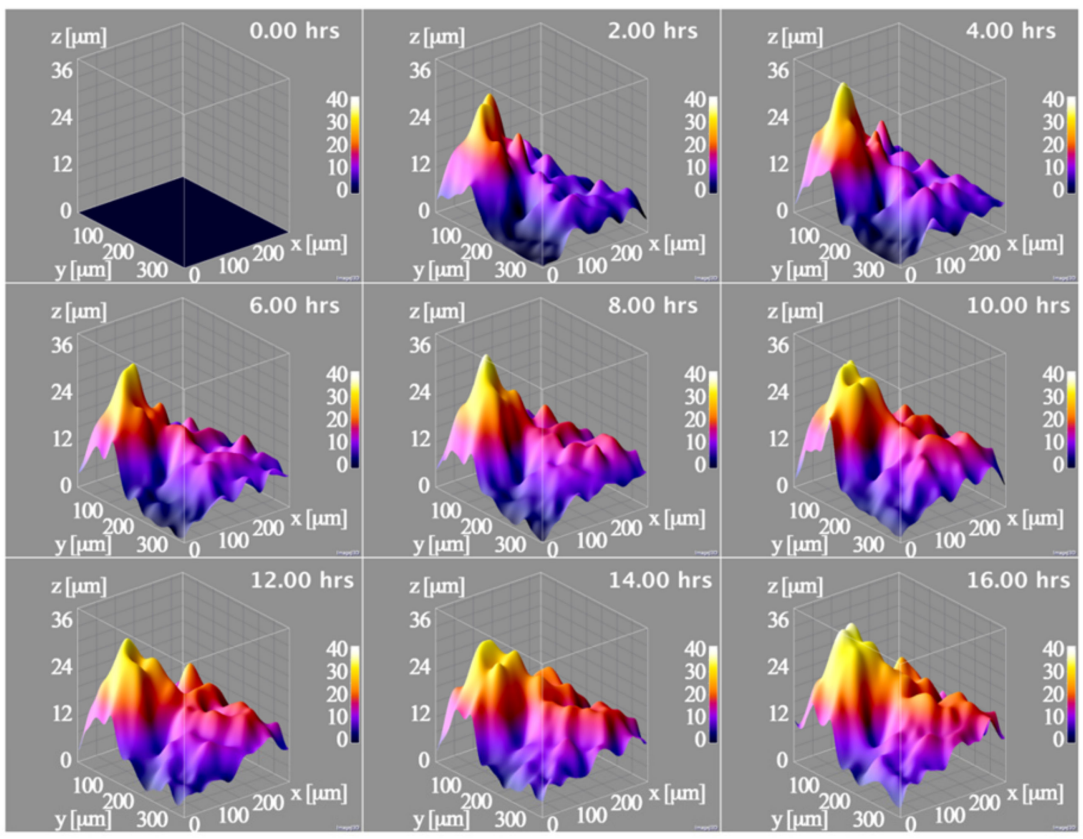

b

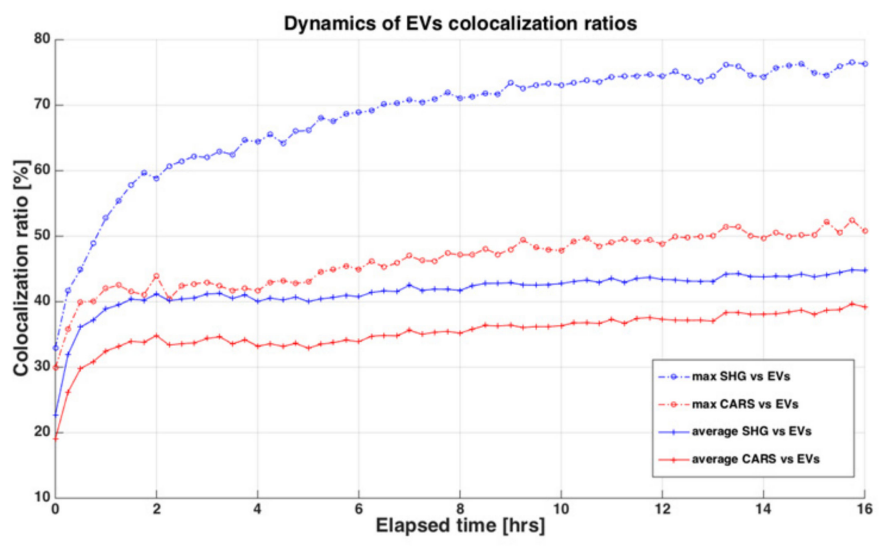

Figure 5. ASC-EVs diffusion in OA cartilage cells and matrix. (a) 3D surfaces showing the EVs penetration depths extracted from the acquired 3D imaging. In the upper corner are visible the corresponding time in the time-lapse experiment. The 3D surface graphs are obtained from the extracted EVs penetration depths images using the ImageJ3D plugin setting smoothing value at 10 pixels. (b) Dynamics of the co-localization ratios between the cells and the lipidic structure (CARS) and the EVs in red and between the collagen (SHG) in the ECM and the EVs in blue. For each ratio is reported the average (continuous line) and the maximum value (dash-dotted line) in the $\mathrm{Z}$ stack for that time step.

The EVs were present in both the cells (CARS signal from lipid structures) and the extracellular matrix (ECM) (SHG signal from collagen) with a highest prevalence in the latter. This effect could be also observed analyzing the co-localization ratios of the EVs with respect to CARS signal and to SHG signal (Figure 5b). Even the co-localization ratios increased with the time during the experiment with a faster pace in the initial steps of the time-lapse and a gradually slowing down towards the plateau. 


\section{Discussion}

The main findings of the present study are the OA-cartilage protective potential of the EV-embedded miRNAs released from adipose-derived mesenchymal stem cells subjected to preconditioning with IL-1 $\beta$, together with their ability to quickly penetrate into cartilage.

Of note to envision clinical and off-the-shelf use of ASC-EVs, agreement was observed between the results obtained in the present work using ASCs from local hip fat and those previously published, with ASCs obtained from abdomen liposuction [5]. In fact, the list of the 100 more expressed EV-embedded miRNA in basal condition identified in the present study showed a $78 \%$ of matching with the previously published data of our research group [5], which in turn showed a $71-73 \%$ of agreement with another recently published dataset [20]. These results reinforce the concept that ASCs contain EVs with a stable miRNA content, regardless of the site of adipose tissue harvest, with a consistent reproducibility among different donors, even with respect to different ages.

As previously observed following IFN $\gamma$ stimulation [9], the treatment with IL-1 $\beta$ does not induce strong changes in the cargo of the ASC-EVs in terms of inflammatory regulators, but it prompts the ASCs to up-regulate or produce miRNAs with chondro-protective potential, rather than to down-regulate or silence miRNAs with pro-inflammatory features.

In particular, miR-146a-5p and miR-520c-3p showed the highest and similar upregulation (about 32-33 Fc) after priming with IL-1 $\beta$. miR-146a was reported as related to OA pathogenesis and prevalence [21], according to OA severity. In fact, it is particularly expressed in low-grade OA cartilage and inversely correlated with cartilage degeneration in late-stage OA cartilage [22-25]. The expression of miR-146a-5p is induced by pro-inflammatory stimuli, particularly IL- $1 \beta$, and it is involved in the regulation of both catabolic and anabolic processes driving cartilage homeostasis, neo-angiogenesis, and inflammatory functions in cartilage and synovium $[24,26,27]$. At experimental level, miR-146a is highly upregulated in IL-1 $\beta$ treated chondrocytes, in surgically-induced osteoarthritis in animals, and in response to mechanical stress [28,29]. Furthermore, miR-146a directly decreases Smad4 expression in chondrocytes, thereby disrupting signal transduction of TGF $\beta$, resulting in an increase of VEGF and reduced cellularity in cartilage tissue [28].

The other highly up-regulated miRNA, miR-520c-3p, was found to be involved in the promotion of Wnt signaling, in the regulation of the inflammatory response and of the chondrogenic process [30].

Among other miRNAs of interest, miR-155-5p interacts with the greatest number of up-regulated or activated genes and it is supposed to be involved in aging, oxidative stress, modulation of Wnt pathway and inflammatory response. Notably, over expression of miR-155-5p and miR-146a was observed in synovial tissue and synovial fibroblasts derived from patients with rheumatoid arthritis in comparison to OA samples [31]. Moreover, the expression of these miRNA is up-regulated in synovial fibroblasts following stimulation with pro inflammatory mediators and its over expression indirectly counteracts the MMP-1 and -3 induction by pro-inflammatory cytokines, suggesting a protective role in arthritic joints $[31,32]$.

Similar to what observed for the up-regulated miRNAs, some activated by IL-1 $\beta$ appeared as potentially involved in cartilage homeostasis such as miR-377-3p, miR-127$5 \mathrm{p}$ and miR-483-3p [33]. In particular, the latter was down-regulated in hypertrophic chondrocytes [34] but it was up-regulated in human and mouse OA tissues, suggesting a reparative role of this miRNA achieved through the promotion of an anabolic response and the inhibition of hypertrophic differentiation [10,33,35,36]. miR-127-5p, also playing a central role in cartilage homeostasis, was significantly down-regulated by IL- $1 \beta$ in human OA chondrocytes [37] and behaved as a suppressor of MMP-13 and IL-1 $\beta$-mediated catabolic effects in chondrocytes [38].

Among the miRNAs silenced by IL-1 $\beta$ priming, miR-23b-and miR-378a-5p have a relevant role in $\mathrm{OA}$, with the former being involved in chondrocyte differentiation and cartilage homeostasis [33,39], and the latter considered as a marker of late-stage OA [40]. 
Overall, several signaling pathways such as Wnt, TGF $\beta$, Hippo, Notch and IHH, representing promising target for OA therapy [41], are stimulated by IL-1 $\beta$ in ASCs and shared with the ones activated by chondrocytes in presence of the same inflammatory stimulus. As a consequence, in chondrocytes there are a plethora of chondro-destructive processes and molecules activated by the cross talk of IL- $1 \beta$ with these pathways [4] that promote alteration of cartilage homeostasis, anabolic processes [42-45] and hypertrophic differentiation of chondrocytes [46] and that could be targeted by the miRNAs observed in IL-1 $\beta$ stimulated ASCs.

To result in a clinically effective product, the chondro-protective miRNA cargo of the EVs derived from IL- $1 \beta$-primed ASCs must reach the target cells, crossing a complex matrix such as that of cartilaginous tissue. In this regard, it has been observed that the EVs derived from ASCs have the ability to fast penetrate for several micrometers into the cartilage, arriving predominantly at the matrix, but also reaching the cells. Herein presented results confirmed the quick EVs penetration along 30-40 $\mu \mathrm{m}$ depth already observed after a $5 \mathrm{~h}$ time-lapse in both micromasses and cartilage explants with the same technology [13], and further extended both intensity and spatial distribution measurements up to $16 \mathrm{~h}$. Moreover, the observation of two diffusion kinetics of EVs suggests an active and steady initial process, followed by a more passive and slower one, which could be linked both to the differences in EVs penetration in the collagen-rich areas, but also to the progressive achievement of saturation, considering the $16 \mathrm{~h}$ as the identified time point when the signal reached a plateau. Finally, the highest EVs prevalence in ECM than in cells observed in experiments conducted on cartilage explants was not previously observed in micromasses [13], where a more homogenous EVs diffusion was reported. These data evidencing differences in EVs kinetics between the two 3D in vitro models might be due to the different cell to matrix ratios and local homogeneity, both higher in micromasses, and suggest the use of cartilage specimens for kinetic studies being more representative of the real cartilage physiology. Starting from these results, further functional studies, through potency and distribution assays, related to the EVs dose-effects will help to better define the optimal dosage and administration frequency to achieve a relevant clinical efficacy for the OA treatment.

\section{Conclusions}

Extracellular vesicles obtained from ASCs isolated from subcutaneous adipose tissue and preconditioned with IL-1 $\beta$ have a chondro-protective miRNA content and are able to fast penetrate cartilage, mainly in collagen-rich areas, likely reaching a tissue saturation after $16 \mathrm{~h}$ of administration.

Supplementary Materials: The following are available online at https:/ /www.mdpi.com/article/ 10.3390/cells10051180/s1, Table S1: normalized CRT values for detected EV-embedded miRNAs, Table S2: target genes of miRNAs up-regulated in ASCs treated with IL-1 $\beta$, Table S3: target genes of miRNAs activated in ASCs treated with IL-1 $\beta$, Table S4: target genes of miRNAs down-regulated in ASCs treated with IL-1 $\beta$, Table S5: target genes of miRNAs silenced in ASCs treated with IL-1 $\beta$, Table S6: fitting parameters related to the EVs average depth, occupied area and occupied volume are listed. The Equation (1) corresponds to the double exponential function used to fit the experimental data, while the Equation (2) corresponds to the single exponential function. For each fitting equation are showed the computed parameters and the Sum of the Squared Errors (SSE) and the coefficient of determination (R2).

Author Contributions: Conceptualization, A.C. and E.R.; methodology, A.C., E.R., L.M.; formal analysis, A.C., E.R., L.M.; investigation, A.C., E.R., L.M., M.V., F.L., C.P.O.; resources, M.B.-B.; data curation, A.C., E.R., L.M.; writing-original draft preparation, A.C.; writing—review and editing, E.R., L.M., M.V., F.L., C.P.O., M.B.-B., L.d.G.; supervision, L.d.G.; project administration, A.C.; funding acquisition, L.d.G. All authors have read and agreed to the published version of the manuscript. 
Funding: This research was funded by the Italian Ministry of Health, "Ricerca Corrente" which had no role in the design of the study and collection, analysis, and interpretation of data and in writing the manuscript.

Institutional Review Board Statement: The study was conducted according to the guidelines of the Declaration of Helsinki, and approved by by the local Institutional Review Board (M-SPER-015).

Informed Consent Statement: Informed consent was obtained from all subjects involved in the study.

Data Availability Statement: The datasets generated during and/or analysed during the current study are available in the OSF repository: https: / / osf.io/zde6p/?view_only=4a627ce15e3c42c4a926 e3194cdb59d9, accessed on 1 February 2021.

Acknowledgments: The authors are grateful to Giovanna Chiorino for the support in the bioinformatics analysis of the data.

Conflicts of Interest: The authors declare no conflict of interest.

\section{References}

1. Loeser, R.F.; Goldring, S.R.; Scanzello, C.R.; Goldring, M.B. Osteoarthritis: A disease of the joint as an organ. Arthritis Rheum. 2012, 64, 1697-1707. [CrossRef] [PubMed]

2. Lopa, S.; Colombini, A.; Moretti, M.; de Girolamo, L. Injective mesenchymal stem cell-based treatments for knee os-teoarthritis: From mechanisms of action to current clinical evidences. Knee Surg. Sports Traumatol. Arthrosc. 2019, 27, 2003-2020. [CrossRef] [PubMed]

3. De Luca, P.; Kouroupis, D.; Viganò, M.; Perucca-Orfei, C.; Kaplan, L.; Zagra, L.; de Girolamo, L.; Correa, D.; Colombini, A. Human Diseased Articular Cartilage Con-tains a Mesenchymal Stem Cell-Like Population of Chondroprogenitors with Strong Immunomodulatory Responses. J. Clin. Med. 2019, 8, 423. [CrossRef] [PubMed]

4. Jenei-Lanzl, Z.; Meurer, A.; Zaucke, F. Interleukin-1beta signaling in osteoarthritis—chondrocytes in focus. Cell Signal 2019, 53, 212-223. [CrossRef]

5. Ragni, E.; Perucca Orfei, C.; De Luca, P.; Colombini, A.; Viganò, M.; de Girolamo, L. Secreted Factors and EV-miRNAs Orchestrate the Healing Capacity of Adipose Mesenchymal Stem Cells for the Treatment of Knee Osteoarthritis. Int. J. Mol. Sci. 2020, $21,1582$. [CrossRef]

6. Colombini, A.; Orfei, C.P.; Kouroupis, D.; Ragni, E.; De Luca, P.; Viganò, M.; Correa, D.; de Girolamo, L. Mesenchymal stem cells in the treatment of articular cartilage degeneration: New biological insights for an old-timer cell. Cytotherapy 2019, 21, 1179-1197. [CrossRef]

7. Kouroupis, D.; Sanjurjo-Rodriguez, C.; Jones, E.; Correa, D. Mesenchymal Stem Cell Functionalization for Enhanced Therapeutic Applications. Tissue Eng. Part B Rev. 2019, 25, 55-77. [CrossRef]

8. Cheng, A.; Choi, D.; Lora, M.; Shum-Tim, D.; Rak, J.; Colmegna, I. Human multipotent mesenchymal stromal cells cytokine prim-ing promotes RAB27B-regulated secretion of small extracellular vesicles with immunomodulatory cargo. Stem Cell Res. Ther. 2020, 11, 539. [CrossRef]

9. Ragni, E.; Perucca Orfei, C.; De Luca, P.; Mondadori, C.; Viganò, M.; Colombini, A.; de Girolamo, L. Inflammatory priming enhances mesenchymal stromal cell secretome potential as a clinical product for regenerative medicine approaches through secreted factors and EV-miRNAs: The example of joint disease. Stem Cell Res. Ther. 2020, 11, 165. [CrossRef]

10. Sondag, G.R.; Haqqi, T.M. The Role of MicroRNAs and Their Targets in Osteoarthritis. Curr. Rheumatol. Rep. 2016, 18, 1-15. [CrossRef]

11. Beyer, C.; Zampetaki, A.; Lin, N.-Y.; Kleyer, A.; Perricone, C.; Iagnocco, A.; Distler, A.; Langley, S.R.; Gelse, K.; Sesselmann, S.; et al. Signature of circulating microRNAs in osteoarthritis. Ann. Rheum. Dis. 2014, 74, e18. [CrossRef]

12. Nugent, M. MicroRNAs: Exploring new horizons in osteoarthritis. Osteoarthr. Cartil. 2016, 24, 573-580. [CrossRef]

13. Mortati, L.; de Girolamo, L.; Perucca Orfei, C.; Viganò, M.; Brayda-Bruno, M.; Ragni, E.; Colombini, A. In Vitro Study of Extracellular Vesicles Migration in Cartilage-Derived Osteoarthritis Samples Using Real-Time Quantitative Multimodal Nonlinear Optics Imaging. Pharmaceutics 2020, 12, 734. [CrossRef] [PubMed]

14. Stanco, D.; De Girolamo, L.; Sansone, V.; Moretti, M. Donor-matched mesenchymal stem cells from knee infrapatellar and subcutaneous adipose tissue of osteoarthritic donors display differential chondrogenic and osteogenic commitment. Eur. Cells Mater. 2014, 27, 298-311. [CrossRef]

15. Ragni, E.; Colombini, A.; De Luca, P.; Libonati, F.; Viganò, M.; Orfei, C.P.; Zagra, L.; de Girolamo, L. miR-103a-3p and miR-22-5p Are Reliable Reference Genes in Extracellular Vesicles from Cartilage, Adipose Tissue, and Bone Marrow Cells. Front. Bioeng. Biotechnol. 2021, 9. [CrossRef]

16. Ragni, E.; Orfei, C.P.; De Luca, P.; Lugano, G.; Viganò, M.; Colombini, A.; Valli, F.; Zacchetti, D.; Bollati, V.; de Girolamo, L. Interaction with hyaluronan matrix and miRNA cargo as contributors for in vitro potential of mesenchymal stem cell-derived extracellular vesicles in a model of human osteoar-thritic synoviocytes. Stem Cell Res. Ther. 2019, 10, 109. [CrossRef] 
17. D'haene, B.; Mestdagh, P.; Hellemans, J.; Vandesompele, J. miRNA expression profiling: From reference genes to global mean normalization. Methods Mol. Biol. 2012, 822, 261-272. [PubMed]

18. Licursi, V.; Conte, F.; Fiscon, G.; Paci, P. Mienturnet: An interactive web tool for microRNA-target enrichment and network-based analysis. BMC Bioinf. 2019, 20, 545. [CrossRef]

19. Mortati, L.; Divieto, C.; Sassi, M.P. CARS and SHG microscopy to follow collagen production in living human corneal fibro-blasts and mesenchymal stem cells in fibrin hydrogel 3D cultures. J. Raman Spectrosc. 2012, 43, 675-680. [CrossRef]

20. Nazari-Shafti, T.Z.; Neuber, S.; Duran, A.G.; Exarchos, V.; Beez, C.M.; Meyborg, H.; Krüger, K.; Wolint, P.; Buschmann, J.; Böni, R.; et al. MiRNA Profiles of Extracellular Vesicles Secreted by Mesenchymal Stromal Cells-Can They Predict Potential Off-Target Effects? Biomolecules 2020, 10, 1353. [CrossRef]

21. Rousseau, J.C.; Millet, M.; Croset, M.; Sornay-Rendu, E.; Borel, O.; Chapurlat, R. Association of circulating microRNAs with preva-lent and incident knee osteoarthritis in women: The OFELY study. Arthritis Res. Ther. 2020, 22, 2. [CrossRef] [PubMed]

22. Skrzypa, M.; Szala, D.; Gablo, N.; Czech, J.; Pajak, J.; Kopanska, M.; Trzeciak, M.; Gargasz, K.; Snela, S.; Zawlik, I. miRNA-146a-5p is upregulated in serum and cartilage samples of patients with osteoarthritis. Pol. J. Surg. 2018, 91, 1-5. [CrossRef] [PubMed]

23. Kopańska, M.; Szala, D.; Czech, J.; Gabło, N.; Gargasz, K.; Trzeciak, M.; Zawlik, I.; Snela, S. MiRNA expression in the cartilage of patients with osteoarthritis. J. Orthop. Surg. Res. 2017, 12, 51. [CrossRef] [PubMed]

24. Yamasaki, K.; Nakasa, T.; Miyaki, S.; Ishikawa, M.; Deie, M.; Adachi, N.; Yasunaga, Y.; Asahara, H.; Ochi, M. Expression of MicroRNA-146a in osteoarthritis cartilage. Arthritis Rheum. 2009, 60, 1035-1041. [CrossRef]

25. Jones, S.W.; Watkins, G.; Le Good, N.; Roberts, S.; Murphy, C.L.; Brockbank, S.M.V.; Needham, M.R.C.; Read, S.J.; Newham, P. The identification of differentially expressed mi-croRNA in osteoarthritic tissue that modulate the production of TNF-alpha and MMP13. Osteoarthritis Cartilage 2009, 17, 464-472. [CrossRef]

26. Wu, C.; Tian, B.; Qu, X.; Liu, F.; Tang, T.; Qin, A.; Zhu, Z.; Dai, K. MicroRNAs play a role in chondrogenesis and osteoarthritis (Review). Int. J. Mol. Med. 2014, 34, 13-23. [CrossRef]

27. Li, X.; Gibson, G.; Kim, J.S.; Kroin, J.; Xu, S.; Van Wijnen, A.J.; Im, H.J. MicroRNA-146a is linked to pain-related pathophysiology of osteoarthritis. Gene 2011, 480, 34-41. [CrossRef]

28. Li, J.; Huang, J.; Dai, L.; Yu, D.; Chen, Q.; Zhang, X.; Dai, K. miR-146a, an IL-1 $\beta$ responsive miRNA, induces vascular endothelial growth factor and chondrocyte apoptosis by targeting Smad4. Arthritis Res. Ther. 2012, 14, R75. [CrossRef]

29. Jin, L.; Zhao, J.; Jing, W.; Yan, S.; Wang, X.; Xiao, C.; Ma, B. Role of miR-146a in human chondrocyte apoptosis in response to mechan-ical pressure injury in vitro. Int. J. Mol. Med. 2014, 34, 451-463. [CrossRef]

30. Stelcer, E.; Kulcenty, K.; Rucinski, M.; Jopek, K.; Richter, M.; Trzeciak, T.; Suchorska, W.M. The Role of MicroRNAs in Early Chondrogenesis of Human Induced Pluripotent Stem Cells (hiPSCs). Int. J. Mol. Sci. 2019, 20, 4371. [CrossRef]

31. Stanczyk, J.; Pedrioli, D.M.L.; Brentano, F.; Sanchez-Pernaute, O.; Kolling, C.; Gay, R.E.; Detmar, M.; Gay, S.; Kyburz, D. Altered expression of MicroRNA in syno-vial fibroblasts and synovial tissue in rheumatoid arthritis. Arthritis Rheum 2008, 58, 1001-1009. [CrossRef]

32. Tili, E.; Michaille, J.-J.; Cimino, A.; Costinean, S.; Dumitru, C.D.; Adair, B.; Fabbri, M.; Alder, H.; Liu, C.G.; Calin, G.A.; et al. Modulation of miR-155 and miR-125b Levels following Lipopolysaccharide/TNF- $\alpha$ Stimulation and Their Possible Roles in Regulating the Response to Endotoxin Shock. J. Immunol. 2007, 179, 5082-5089. [CrossRef]

33. Iliopoulos, D.; Malizos, K.N.; Oikonomou, P.; Tsezou, A. Integrative MicroRNA and Proteomic Approaches Identify Novel Osteoarthritis Genes and Their Collaborative Metabolic and Inflammatory Networks. PLoS ONE 2008, 3, e3740. [CrossRef]

34. McAlinden, A.; Varghese, N.; Wirthlin, L.; Chang, L.-W. Differentially Expressed MicroRNAs in Chondrocytes from Distinct Regions of Developing Human Cartilage. PLoS ONE 2013, 8, e75012. [CrossRef]

35. Qi, Y.; Ma, N.; Yan, F.; Yu, Z.; Wu, G.; Qiao, Y.; Han, D.; Xiang, Y.; Li, F.; Wang, W.; et al. The expression of intronic miRNAs, miR-483 and miR-483*, and their host gene, Igf2, in murine osteoarthritis cartilage. Int. J. Biol. Macromol. 2013, 61, 43-49. [CrossRef]

36. Díaz-Prado, S.; Cicione, C.; Muiños-López, E.; Hermida-Gómez, T.; Oreiro, N.; Fernández-López, C.; Blanco, F.J. Characterization of microRNA expres-sion profiles in normal and osteoarthritic human chondrocytes. BMC Musculoskelet Disord. 2012, 13, 144. [CrossRef]

37. Akhtar, N.; Rasheed, Z.; Ramamurthy, S.; Anbazhagan, A.N.; Voss, F.R.; Haqqi, T.M. MicroRNA-27b regulates the expression of matrix metalloproteinase 13 in human osteoarthritis chondrocytes. Arthritis Rheum. 2010, 62, 1361-1371. [CrossRef]

38. Park, S.J.; Cheon, E.J.; Lee, M.H.; Kim, H.A. MicroRNA-127-5p regulates matrix metalloproteinase 13 expression and inter-leukin1beta-induced catabolic effects in human chondrocytes. Arthritis Rheum. 2013, 65, 3141-3152. [CrossRef]

39. Ham, O.; Lee, C.Y.; Song, B.W.; Lee, S.Y.; Kim, R.; Park, J.H.; Lee, J.; Seo, H.-H.; Lee, C.Y.; Chung, Y.-A.; et al. Upregulation of miR-23b enhances the autologous therapeutic poten-tial for degenerative arthritis by targeting PRKACB in synovial fluid-derived mesenchymal stem cells from patients. Mol. Cells 2014, 37, 449-456. [CrossRef]

40. Li, Y.-H.; Tavallaee, G.; Tokar, T.; Nakamura, A.; Sundararajan, K.; Weston, A.; Sharma, A.; Mahomed, N.; Gandhi, R.; Jurisica, I.; et al. Identification of synovial fluid microRNA signature in knee osteoarthritis: Differentiating early- and late-stage knee osteoarthritis. Osteoarthr. Cartil. 2016, 24, 1577-1586. [CrossRef]

41. Wang, Y.; Fan, X.; Xing, L.; Tian, F. Wnt signaling: A promising target for osteoarthritis therapy. Cell Commun. Signal. 2019, 17, 1-14. [CrossRef] 
42. Fan, Z.; Yang, H.; Bau, B.; Soder, S.; Aigner, T. Role of mitogen-activated protein kinases and NFkappaB on IL-1beta-induced effects on collagen type II, MMP-1 and 13 mRNA expression in normal articular human chondrocytes. Rheumatol. Int. 2006, 26, 900-903. [CrossRef]

43. Zhong, L.; Schivo, S.; Huang, X.; Leijten, J.; Karperien, M.; Post, J.N. Nitric Oxide Mediates Crosstalk between Interleukin 1beta and WNT Signaling in Primary Human Chondrocytes by Reducing DKK1 and FRZB Expression. Int. J. Mol. Sci. 2017, 18, 2491. [CrossRef]

44. Kim, H.A.; Cho, M.-L.; Choi, H.Y.; Yoon, C.S.; Jhun, J.Y.; Oh, H.J.; Kim, H.-Y. The catabolic pathway mediated by Toll-like receptors in human osteoarthritic chondrocytes. Arthritis Rheum. 2006, 54, 2152-2163. [CrossRef]

45. Ying, W.; Yuan, F.; He, P.; Ji, P. Inhibition of Notch1 protects against IL-1beta-induced inflammation and cartilage de-struction in temporomandibular chondrocytes. Mol. Med. Rep. 2017, 15, 4391-4397. [CrossRef]

46. Ha, Y.J.; Choi, Y.S.; Kang, E.H.; Shin, K.; Kim, T.K.; Song, Y.W.; Lee, Y.J. SOCS1 suppresses IL-1beta-induced C/EBPbeta expression via transcriptional regulation in human chondrocytes. Exp. Mol. Med. 2016, 48, e241. [CrossRef] 